\title{
Serum Proteins Alter the Ability of Neutrophils to Phagocytose Malaria Related Hemozoin Crystals
}

\author{
Danielle Lazarin-Bidóia $^{1 *}$, Rayanne Regina Beltrame Machado ${ }^{1}$, Celso Vataru Nakamura ${ }^{1}$, Hans \\ Joachim Anders ${ }^{2}$, Stefanie Steiger ${ }^{2}$ and Sueli de Oliveira Silva Lautenschlager ${ }^{1}$ \\ 1. Technological Innovation Laboratory in the Development of Pharmaceuticals and Cosmetics, \\ Department of Basic Health Sciences, State University of Maringá, Maringá, Paraná, Brazil. \\ 2. Nephrologisches Zentrum, Medizinische Klinik und Poliklinik IV, Klinikum der \\ Ludwig Maximilians Universität-Innenstadt, Munich, Germany. \\ * Corresponding author: dlbidoia@gmail.com
}

Malarial hemozoin is an insoluble crystalline pigment, derived from Plasmodium digesting-host haemoglobin in malaria disease. Death of plasmodium releases hemozoin crystals into the bloodstream of the host leading to oxidative burst in leukocytes and further inflammation that can damage host tissue [1]. Studies focused their efforts on the pathological base of the severe manifestation of malaria that happens when infected red blood cells adhere to endothelial cells in the microcirculation of different organs impairing the blood flow and activating immune cells [2]. Neutrophils play an important role in host defense-related local and systemic inflammation, however information on the interaction between hemozoin and circulating neutrophils are limited. Thus, our goal was to study the interaction of hemozoin crystals with human neutrophils and hypothesized that serum proteins may affect the phagocytic capacity of neutrophils. For this, neutrophils were incubated with 50 and $100 \mu \mathrm{g} / \mathrm{ml}$ hemozoin in the presence or not of $30 \%$ human serum for $2 \mathrm{~h}$. After, the cells were fixed in a solution of $2.5 \%$ glutaraldehyde in $0.1 \mathrm{M}$ cacodylate buffer for $24 \mathrm{~h}$ at $4{ }^{\circ} \mathrm{C}$. For the SEM, the cells were dehydrated in increasing concentrations of etanol, critical pointdried in $\mathrm{CO}_{2}$, sputter-coated with gold and observed using a FEI Scios. For TEM, the cells were postfixed in a solution of $1 \% \mathrm{OsO}_{4}, 0.8 \%$ potassium ferricyanide and $10 \mathrm{mM} \mathrm{CaCl} 2$ in $0.1 \mathrm{M}$ cacodylate buffer. The samples were dehydrated in increasing acetone gradient and embedded in Polybed 812 resin. Ultrathin sections were then obtained, contrasted with uranyl acetate and lead citrate, and observed in JEOL JEM 1400. We showed that hemozoin crystals are phagocytosed by neutrophils and induce neutrophils death by disrupting nuclear and cellular membrane and inducing decrease of granules and increase of vacuoles in the cytoplasm compared to neutrophils alone. As hemozoin crystals are release in the blood stream we hypothesized that serum protein might alter the phagocytic potential of neutrophils. As we expected, the incubation of neutrophils and hemozoin crystals in the presence of serum protein decreased neutrophils ability to phagocytosis, decrease the structural changes and consequently the signs of neutrophils death. Consequently, we observed less neutrophil cell death. In conclusion, serum proteins might interact or bind to hemozoin crystals in the blood, therefore neutrophils may not be able to recognize hemozoin crystals as danger signal resulting in impaired clearance and this could be a possible reason for inflammatory disease burden in malaria.

References:

[1] L.M. Coronado, C.T. Nadovich and C. Spadafora, Biochim Biophys Acta 6 (2014), p. 20322041.

[2] B. Autino et al., Mediterr J Hematol Infect Dis 4 (2012), p. e2012061.

[3] The authors acknowledge funding from the COMCAP-UEM, CNPq, CAPES, PRONEX/Fundação Araucária, FINEP. 

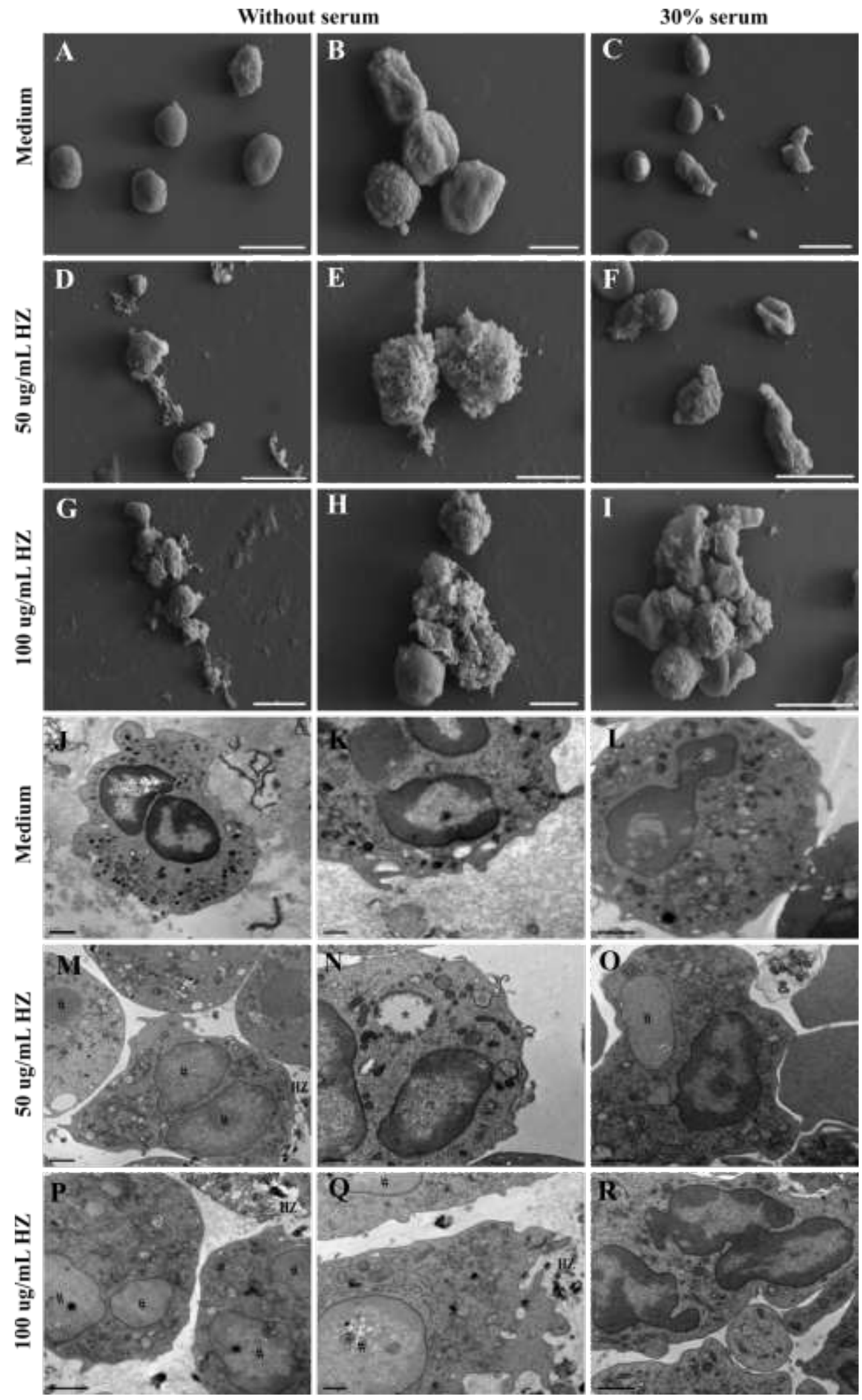

Figure 1. Morphological and ultrastructural alterations in neutrophils incubated with hemozoin for 2 $h$ in the presence or not of human serum. (A-I) SEM images. (J-R) TEM images. (A,B,J,K) untreated neutrophils. (C,L) untreated neutrophils plus 30\% serum. (D,E,M,N) neutrophils treated with 50 $\mathrm{g} / \mathrm{mL}$. (F,O) neutrophils plus $30 \%$ serum treated with $50 \mu \mathrm{g} / \mathrm{mL}$. $(\mathrm{G}, \mathrm{H}, \mathrm{P}, \mathrm{Q})$ neutrophils treated with $100 \mu \mathrm{g} / \mathrm{mL}$. (I,R) neutrophils plus 30\% serum treated with $100 \mu \mathrm{g} / \mathrm{mL}$. \#: loss of heterochromatin. *: presence of vacuoles. HZ: hemozoin. Scale bars $=10 \mu \mathrm{m}$ in A,B,D,E,G,H; $5 \mu \mathrm{m}$ in C,F,I; $1 \mu \mathrm{m}$ in $\mathrm{J}, \mathrm{K}, \mathrm{M}, \mathrm{N}, \mathrm{P}, \mathrm{Q} ; 0.5 \mu \mathrm{m}$ in $\mathrm{L}, \mathrm{O}, \mathrm{R}$. 